\title{
Correlations of inhaled NO with the cTnI levels and the plasma clotting factor in rabbits with acute massive pulmonary embolism ${ }^{1}$
}

\author{
Zeming Zhang', Zibo Meng", Yancun Wang ${ }^{\prime \prime \prime}$
}

'PhD, Department of Respiratory Medicine, Affiliated Zhou Pu Hospital, Shanghai Health Medical College, China. Design of the study, acquisition of data, technical procedures, statistical analysis, manuscript preparation.

"Master, Department of Respiration, Affiliated Hospital, Hebei University, Baoding, China. Acquisition of data, technical procedures, manuscript preparation.

"'Bachelor, Department of Nerve, Affiliated Zhou Pu Hospital, Shanghai Health Medical College, China. Acquisition of data, technical procedures.

\begin{abstract}
Purpose: To investigate the correlation of inhaled nitric oxide (NO) on plasma levels of cardiac troponin I (cTnI) and von Willebrand factor (VWF), glycoprotein (GP) IIb/IIla, granule membrane protein 140 (GMP-140) in rabbits with acute massive pulmonary embolism (PE). Methods: Thirty apanese white rabbits were divided into 3 groups, thrombus were injected in model group ( $n=10)$, NO were inhalated for $24 \mathrm{~h}$ after massive PE in NO group $(n=10)$, saline were injected in control group $(n=10)$. The concentrations of VWF, GP IIb/IIla, GMP140 and $c T n l$ were tested at 4, 8, 12, 16, 20, and $24 \mathrm{~h}$, Correlation analyses were conducted between cTnl and VWF, GP IIb/IIla, and GMP-140 by Pearson's correlation.

Results: The concentration of cTnI and VWF, GP IIb/IIla, and GMP-140 was increased in the model group, compared to control group. In the inhaled group, the concentrations of cTnl, VWF, GP IIb/IIla, and GMP-140 were reduced compared to model group. There was a positive correlation between cTnI and VWF, GP IIb/IIla, and GMP-140.

Conclusion: Inhaled nitric oxide can lead to a decrease in levels of cardiac troponin I, von Willebrand factor, glycoprotein, and granule membrane protein 140, after an established myocardial damage, provoked by acute massive pulmonary embolism.

Key words: Pulmonary Embolism. Nitric Oxide. von Willebrand Factor. Glycoproteins. Rabbits.
\end{abstract}




\section{Introduction}

The mortality rate of acute massive pulmonary thromboembolism was about $30 \%^{3-4}$, which was very high ${ }^{1,2}$, particularly in patients with shock or heart failure,, so the risk of mortality should be assessed as early as possible to maintain more effective treatments $\mathrm{s}^{5-7}$. The European Society of Cardiology has divided the prognostic risk into 3 levels. Right ventricle dysfunction in patients with hemodynamic instability are included in high-risk group ${ }^{5}$, in which cardiac troponin is increased in the pulmonary thromboembolism with heart failure. These factors indicate myocardial damage and poor prognosis but are not well-understood ${ }^{8,9}$.

Massive pulmonary embolism (MPE) causes damage to vascular endothelial, induced platelet, and coagulation system activation ${ }^{10}$, as well as some coagulation factors ${ }^{11,12}$, which would lead to further deterioration of pulmonary embolism and resulting in severe hypoxia, as well as myocardial damage.

There were some studies have found that inhaled nitric oxide (NO) was a very important treatment in the MPE ${ }^{13,14}$, which can reduce pulmonary arterial pressure as well as reduce neutrophil chelation, promote lung endothelial integrity, improve lung ventilation/ perfusion, increase blood vessels density, and repair vascular endothelial cells to alleviate lung injury ${ }^{15,16}$. In the past 20 years, NO has become one of the most important signaling molecules in the cardiovascular system and is considered as a heart protection mediator ${ }^{17}$.

Above all, we supposed that, since inhaled NO was used to treat MPE through von Willebrand factor (vWF), glycoprotein (GP) llb/ IIla and granule membrane protein 140 (GMP$140)$, it may alleviate the myocardial damage.

In the study, a rabbit model of massive pulmonary thromboembolism was established by emboli injection to detect changes in cardiac troponin I (cTnl), vWF, GP Ilb/IIla, and
GMP-140, as well as the relationships among these molecules. was Additionally, rabbits were treated with inhaled NO to investigate the changes and effects of VWF, GP IIb/IIla, and GMP-140 in MPE and after inhaling NO.

\section{- Methods}

This study was carried out in strict accordance with the recommendations in the Guide for the Care and Use of Laboratory Animals of the National Institutes of Health. The animal use protocol has been reviewed and approved by the Institutional Animal Care and Use Committee (IACUC) of Hebei University.

Thirty standard laboratorial albino Japanese rabbits with large ears, either sex, aged $6-10$ months, and weights of $2-2.8 \mathrm{~kg}$ were provided by Hebei Animal Experimental Center. $N=Z^{2} \times(P \times(1-P)) / E^{2}, \quad(Z=1.56, P=0.1$, $E=0.1), N \approx 20$, so each group should have no less than 10 rabbits. The randomization method was random table. The rabbits were randomly divided into three groups: model group $(n=10)$, the thrombus was made of autologous venous blood and inject through the jugular vein, establish massive pulmonary thromboembolism model; inhaled group $(\mathrm{n}=$ $10)$, the rabbits inhaled $\mathrm{NO}(20 \mathrm{ppm})$ for $24 \mathrm{~h}$ at $2 \mathrm{~h}$ after modeling; control group $(\mathrm{n}=10)$, NS injected through jugular vein into the rabbits.

\section{Model establishing}

After local disinfection, the rabbits were anesthetized with urethane (20\%) $1 \mathrm{~g} /$ kgvia the ear vein for anesthesia, then $0.5 \mathrm{~g} /$ $\mathrm{kg}$ was maintained in full experiment ${ }^{18}$. Then the rabbits were mechanically ventilated by trachea intubation.

Before the operation, $1 \mathrm{ml}$ of blood, drawn from the auricular vein, was transfer into a centrifuge tube, kept for 30 minutes before water bath $\left(70^{\circ} \mathrm{C}, 10\right.$ minutes), then the thrombus was kept (since the supernatant was 
removed) in syringe, and was form into striplike clot into normal saline inaseptic disk by hard and slow press through the needle, the clot was $\phi 1 \mathrm{~mm}$ and was cut into 3-4 mm length, which was mixed with NS to make suspensions when used. Homemade pulmonary artery catheters and microvascular catheters (5Fr TI; Tyler \& Company, Atlanta, GA, USA) were inserted into the right jugular vein and left carotid artery via the anterior chest approach through a transverse incision of $2 \mathrm{~cm}$. Pulmonary artery catheter (homemade) insertion was monitored by an oscilloscope to control the insertion site and saline infusion was maintained at $0.3 \mathrm{~mL} /$ min with a peristaltic pump. The arterial mean pressure and pulmonary artery pressure were measured synchronously with a multi-channel physiological parameter analysis recorder (MP150, BIOPA Systems, Inc., Goleta, CA, USA) through a pressure sensor. The left femoral vein was separated and a microcatheter was inserted for rehydration and blood collection. $0.5 \mathrm{ml}$ thrombus suspension (3-4 clots) was injected through the right jugular vein every 3 min and washed by 2-3 $\mathrm{ml}$ normal saline, until the average arterial blood pressure decreased to $40 \%$ of the base. Diastolic pressure was maintained at 55-60 $\mathrm{mmHg}$ for $40 \mathrm{~min}$, and the massive pulmonary thrombosis with myocardial damage model was successfully established. Mechanical ventilation was not essential during modeling, only when the rabbit was in danger, such as the respiratory rates $>40$ times/min or the SO $2 \%<80 \%$ to control the respiratory rate of 28 times/min and $20 \mathrm{~cm}$ $\mathrm{H}_{2} \mathrm{O}$ of $50 \% \mathrm{O}_{2}$. The control group was injected with saline. The inhaled group inhaled NO (20ppm) after $2 \mathrm{~h}$ of modeling for $24 \mathrm{~h}$. During the experiment, all the rabbits in 3 group took mechanical ventilation, which was performed with a SERVO-ibaby ventilator (Rontgenvagen 2, SE-17154 Solna, Maquet Critical Care AB Company, Solna, Sweden). 2 rabbits were dead during the modeling.
Method of NOI

Following successful modeling, mechanical ventilation was initiated when mPAP reached $40 \%$ and the rabbit exhibited breathlessness or breathing difficulties for 2 h. NO was composed of $800 \times 10-6 \mathrm{~g} / \mathrm{l}$ decompressed NO, nitrogen (N2). When the concentration of $\mathrm{NOI}$ reached 20ppm, a ventilator pipe was connected to the NOI pipe for invasive mechanical ventilation (pressure, $20 \mathrm{~cm}$ water column; respiratory rate, 28 bpm; oxygen concentration with mechanical ventilation, $50 \%$ ). The concentrations of NO and nitrogen dioxide $\left(\mathrm{NO}_{2}\right)$ were continuously monitored using a nitrogen oxide analyzer (Thermo Fisher Scientific, Inc., Waltham, MA, USA) and the level of methemoglobin was also monitored throughout and did not exceed 0.3 g/L.

\section{Pulmonary perfusion and pathology of lung and heart}

After anesthesia and fixation on the rabbit platform, the abdominal aorta of the rabbit was flushed with heparin saline until the liver became white and was then injected with acetone until the color of lung changed. Pulmonary perfusion was conducted with an ABS perfusion agent at $18-25 \mathrm{mmHg}$ using a BIOPAC pressure conditioner. The lung artery was detected with a MicroCT X-ray-3D system for laboratory (A00001514J, PerkinElmer, Waltham, MA, USA) (Figure 1A, B) and both the lung and heart were sampled for pathology.

Detection of cTnl, vWF, GP /Ib/IIla, and GMP140

cTnl was detected by microparticle chemiluminescence method using automatic immune analyzers, vWF and GMP-140 were tested by enzyme-linked immunosorbent assay (Shanghai Sun Biotechnology Company, 
Shanghai, China), and GP Ilb/Illa was examined by flow cytometry. The monoclonal antibody was supplied by BD Biosciences (San Jose, CA, USA). Blood samples were collected before and at $2,4,8,12,16,20$, and $24 \mathrm{~h}$ while monitoring mean pressure and mean pulmonary artery pressure.

\section{Statistical analysis}

All data were processed using the statistics software SPSS20.0 (SPSS, Inc., Chicago, IL, USA). The missing data of the study has been deleted in the statistical analysis. Variations in the normal distribution were shown as mean \pm standard deviation $(\chi \pm s)$, and one-way analysis of variance and the $q$ test were used for comparison. The distribution was tested by Kolmogorov-Smirnov test (KS), if $K-S$ showed the $p>0.05$, we say the variables distributed normally. $\mathrm{P}<0.05$ was considered as with statistical differences.

\section{- Results}

\section{Pathological results}

Lung embolization is shown in Figure 1C and the heart is shown in Figure 1D, E. The right ventricular wall of the model group was thinner than that of the control and inhaled groups; myocardial necrosis and embolism in the heart of the model group were higher than those in the heart of inhaled group in cardiomyopathy (Figure 1F, G).
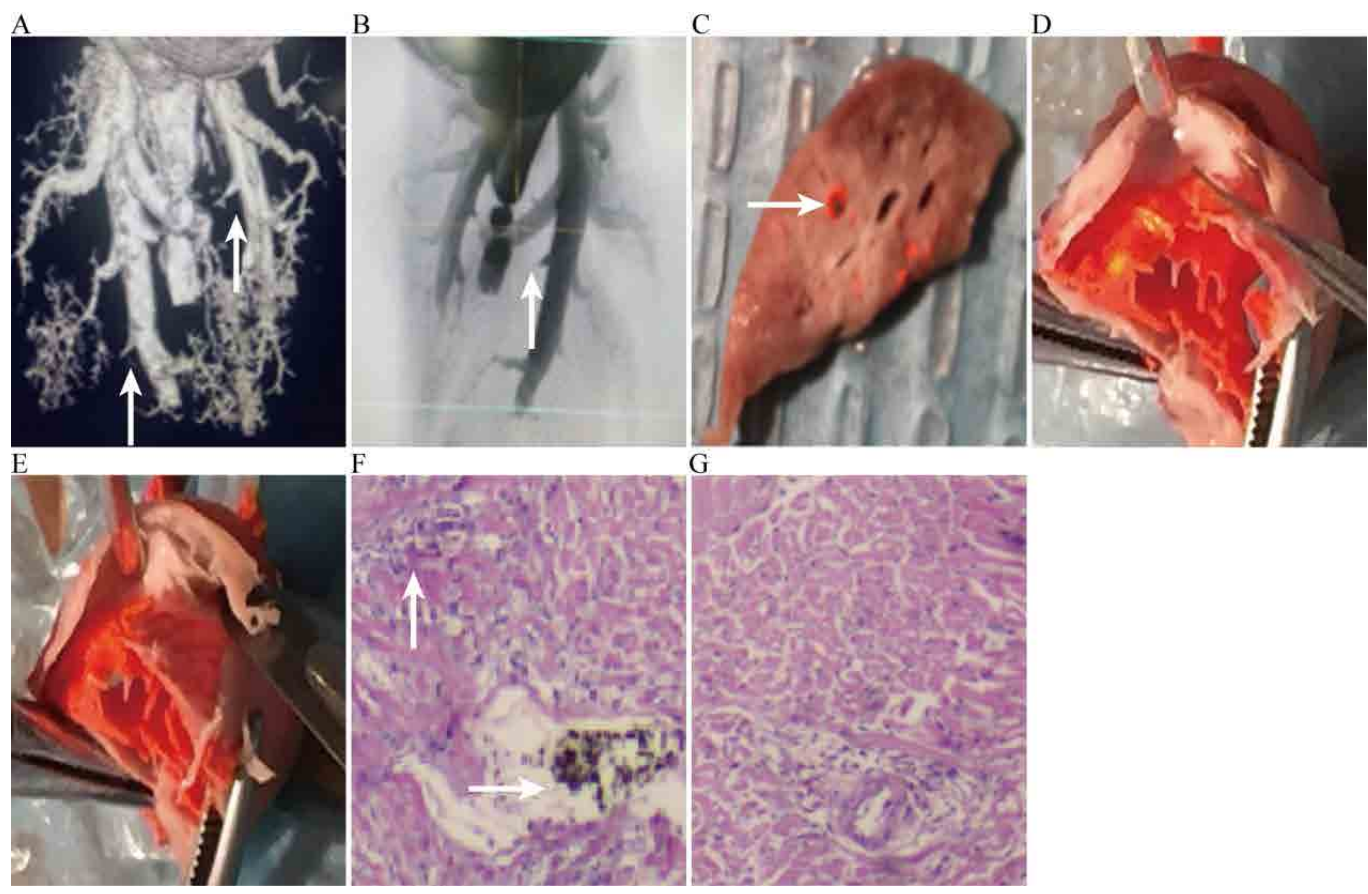

Figure 1 - Pulmonary embolism image and pathology. A,B: Blocked arteries image in MicroCT X-ray-3D system for laboratory; C: Emboli; D: Right ventricle after NO inhalation; E: Right ventricle before NO inhalation; F: Myocardial necrosis pathological changes before NO inhalation; G: Myocardial necrosis pathological changes after NO inhalation.

\section{Changes in plasma cardiac troponin concentration}

The plasma cardiac troponin concentration of acute massive area pulmonary thromboembolism was increased at $2 \mathrm{~h}$, which was clear at $4 \mathrm{~h}$ and reached a peak at $16 \mathrm{~h}(0.46$ $\pm 0.10 \mu \mathrm{g} / \mathrm{L})$. These values were significantly 
higher than those in the inhaled group at each time point $(P<0.05)$, and extremely higher than those in the control group from 4 to $20 \mathrm{~h}$ $(P<0.05)$ (Table 1$)$.

Table 1 - Comparison of plasma CTnl $(\bar{x} \pm \mathrm{s}, \mu \mathrm{g} / \mathrm{ml})$.

\begin{tabular}{lllllllll} 
Group & $\mathbf{0 ~ h}$ & $\mathbf{2} \mathbf{h}$ & $\mathbf{4 h}$ & $\mathbf{8} \mathbf{h}$ & $\mathbf{1 2} \mathbf{h}$ & $\mathbf{1 6} \mathbf{h}$ & $\mathbf{2 0} \mathbf{h}$ & $\mathbf{2 4} \mathbf{h}$ \\
\hline Control & $0.06 \pm 0.01$ & $0.07 \pm 0.01$ & $0.07 \pm 0.01$ & $0.08 \pm 0.01$ & $0.06 \pm 0.01$ & $0.06 \pm 0.01$ & $0.07 \pm 0.01$ & $0.08 \pm 0.01$ \\
Model & $0.08 \pm 0.01$ & $0.12 \pm 0.02$ & $0.21 \pm 0.04^{*}$ & $0.26 \pm 0.08^{*}$ & $0.38 \pm 0.11^{*}$ & $0.46 \pm 0.10^{*}$ & $0.25 \pm 0.09 *$ & $0.13 \pm 0.06^{*}$ \\
Inhaled & $0.07 \pm 0.01$ & $0.11 \pm 0.04$ & $0.13 \pm 0.04$ & $0.14 \pm 0.05$ & $0.25 \pm 0.06$ & $0.19 \pm 0.09$ & $0.15 \pm 0.06$ & $0.12 \pm 0.04$ \\
$\mathrm{~T}$ & & 0.7071 & 4.4721 & 4.0224 & 3.2809 & 6.3464 & 2.9235 & 0.4385 \\
$p$ & & 0.4886 & 0.0003 & 0.0008 & 0.004 & 0.0000 & 0.0091 & 0.6662 \\
\hline
\end{tabular}

Note: T/p values were between model group and inhaled group; $P^{*}<0.05$ : Comparison between the control group and model group.

Change in plasma vWF

Plasma vWF increased from $2 \mathrm{~h}$ and reached a peak at $8 \mathrm{~h}$, which was higher than in the control group from 2 to $16 \mathrm{~h}(P<0.05)$; compared with model group, there was a decrease significantly of VWF in the inhaled group at 4 and $8 \mathrm{~h}(P<0.05)$ (Table 2$)$.

Table 2 - Comparison of plasma vWF (ng/ml), GPIlb/IIla (\%), GMP-140l (\%) levels ( $\bar{x} \pm \mathrm{s})$.

\begin{tabular}{|c|c|c|c|c|c|c|c|c|}
\hline $\begin{array}{l}\text { Group } \\
\text { parameter }\end{array}$ & Oh & $2 h$ & $4 h$ & $8 h$ & $12 \mathrm{~h}$ & $16 h$ & $20 h$ & $24 h$ \\
\hline vWF & $112.3 \pm 24.1$ & $153.8 \pm 26.2$ & $189.7 \pm 29.3$ & $212.7 \pm 28.4$ & $156.4 \pm 25.2$ & $138.4 \pm 26.7$ & $129.5 \pm 27.1$ & $127.7 \pm 25.8$ \\
\hline $\begin{array}{l}\text { ModelG- } \\
\text { PIIb/IIla }\end{array}$ & $2.16 \pm 0.72$ & $14.04 \pm 6.01$ & $16.08 \pm 6.25$ & $18.97 \pm 6.75$ & $20.16 \pm 6.35$ & $23.03 \pm 6.70$ & $17.15 \pm 5.38$ & $14.12 \pm 6.79$ \\
\hline GMP-140 & $16.2 \pm 4.1$ & $31.0 \pm 4.9$ & $33.1 \pm 4.7$ & $35.3 \pm 4.8$ & $36.1 \pm 4.6$ & $30.1 \pm 4.7$ & $29.9 \pm 4.7$ & $29.8 \pm 4.9$ \\
\hline vWF & $113.2 \pm 21.5$ & $111.2 \pm 24.6$ & $110.5 \pm 22.7^{* *}$ & $112.7 \pm 23.8 * *$ & $112.9 \pm 20.9 * *$ & $113.6 \pm 20.5^{* *}$ & $109.5 \pm 23.5$ & $113.7 \pm 23.5$ \\
\hline $\begin{array}{l}\text { ControlG- } \\
\text { PIIb/IIla }\end{array}$ & $2.12 \pm 0.81$ & $2.14 \pm 0.82^{* *}$ & $2.13 \pm 0.79 * *$ & $2.15 \pm 0.80 * *$ & $2.21 \pm 0.74^{* *}$ & $2.18 \pm 0.72^{* *}$ & $2.14 \pm 0.79 * *$ & $2.11 \pm 0.83^{* *}$ \\
\hline GMP-140 & $16.2 \pm 4.1$ & $16.7 \pm 5.1^{* *}$ & $16.7 \pm 5.1^{* *}$ & $17.2 \pm 4.9 * *$ & $16.9 \pm 4.6^{* *}$ & $16.2 \pm 4.8^{* *}$ & $16.9 \pm 4.4^{* *}$ & $16.4 \pm 4.6^{* *}$ \\
\hline vWF & $112.9 \pm 24.8$ & $131.8 \pm 25.1$ & $149.9 \pm 25.2^{*}$ & $142.5 \pm 24.7^{*}$ & $136.2 \pm 27.1$ & $127.5 \pm 25.7$ & $124.1 \pm 26.7$ & $123.8 \pm 25.3$ \\
\hline $\begin{array}{l}\text { NOGPIIb/ } \\
\text { Illa }\end{array}$ & $2.11 \pm 0.90$ & $10.4 \pm 7.1$ & $14.11 \pm 6.05$ & $15.12 \pm 6.25$ & $16.88 \pm 5.21$ & $15.06 \pm 5.90 *$ & $14.12 \pm 5.90$ & $12.10 \pm 6.20$ \\
\hline GMP-140 & $16.2 \pm 4.3$ & $26.9 \pm 5.1$ & $27.7 \pm 4.6^{*}$ & $28.2 \pm 5.5^{*}$ & $25.1 \pm 4.1^{*}$ & $19.8 \pm 3.9 *$ & $18.8 \pm 3.7^{*}$ & $18.9 \pm 3.6^{*}$ \\
\hline T1M-NO & & 1.91 & 3.26 & 5.90 & 1.74 & 0.94 & 0.45 & 0.34 \\
\hline T2M-NO & & 1.24 & 0.72 & 1.32 & 1.26 & 2.82 & 1.20 & 0.70 \\
\hline T3M-NO & & 1.85 & 2.61 & 3.075 & 5.70 & 5.48 & 5.83 & 5.58 \\
\hline P1 M-NO & & 0.073 & 0.004 & 0.000 & 0.098 & 0.365 & 0.659 & 0.737 \\
\hline P2M-NO & & 0.232 & 0.483 & 0.202 & 0.220 & 0.011 & 0.246 & 0.496 \\
\hline P3 M-NO & & 0.0818 & 0.01 & 0.0065 & 0.000 & 0.000 & 0.000 & 0.000 \\
\hline
\end{tabular}

Note: T1M-NO/P1 M-NO: comparison of vWF between Model group and NO group; T2M-NO/P2 M-NO: comparison of GPIIb/IIla between Model group and NO group;T3M-NO/P3 M-NO: comparison of GMP-140 between Model group and NO group; ${ }^{*} \mathrm{p}<0.05$, $* * * p<0.01$ 


\section{Change in plasma GP IIb/IIla}

The plasma GP IIb/IIla concentration of acute massive area pulmonary thromboembolism increased at $2 \mathrm{~h}$ and reached a peak at $16 \mathrm{~h}$, which was significantly higher than in the control group $(P<0.05)$ at each time point; compared with model group, , there was a decrease significantly in the inhaled group at $16 \mathrm{~h}(P<0.05)$ (Table 2).

\section{Change in plasma GMP-140}

The plasma GMP-140 concentration
of acute massive area pulmonary

thromboembolism increased at $2 \mathrm{~h}$ and reached a peak at $16 \mathrm{~h}$, which was significantly higher than that in the control group at each time point $(P<0.05)$; , this value was extremely higher than that in the inhaled NO group from 4 to $20 \mathrm{~h}(P<0.05)$ (Table 2$)$.

\section{Correlation analysis}

There was a significant positive correlation between plasma cardiac troponin peak concentration and plasma peak VWF $(r=$ $0.99, P<0.01), \mathrm{GP} \mathrm{Ilb} / \mathrm{Illa}(r=0.99, P<0.01)$, and GMP-140 $(r=0.93, P<0.05)$ in the model group (Figure 2).
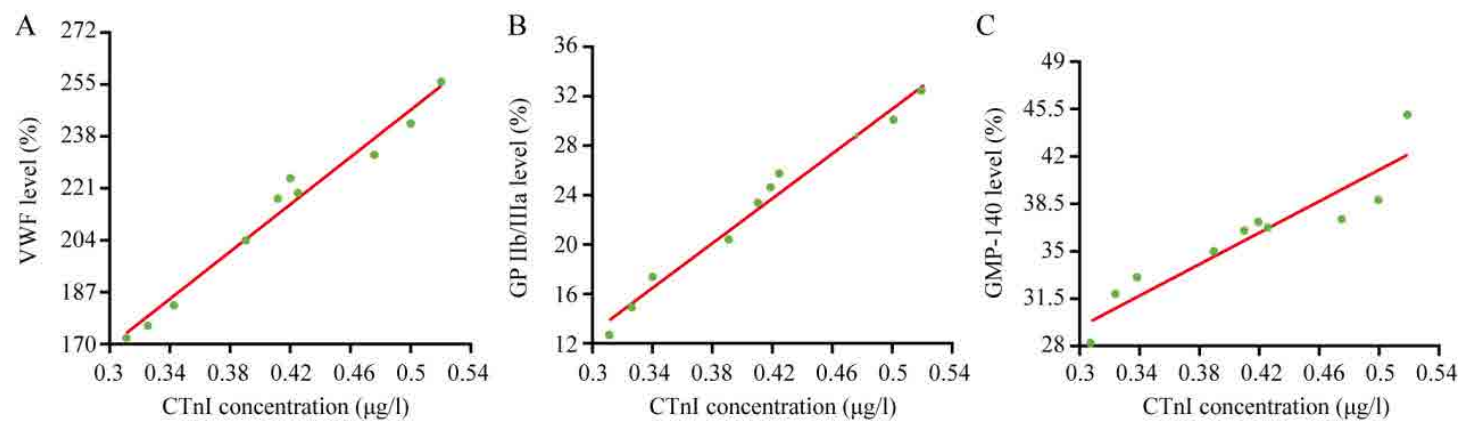

Figure 2 - Correlation between CTnI peak concentration and plasma coagulation system factor. A: Correlation between plasma CTnl peak concentration and GP IIb/IIla; B: Correlation between plasma CTnl peak concentration and GMP-140; C: Correlation between plasma CTnI peak concentration and vWF.

\section{- Discussion}

It has been found that increased cardiac troponin during pulmonary thromboembolism leads to higher mortality ${ }^{9}$. In the study, cardiac troponin levels increased and reached a peak concentration of $0.46 \pm 0.10 \mu \mathrm{g} / \mathrm{L}$, meanwhile plasma vWF, GP IIb/IIla, and GMP140 increased in rabbits after massive area pulmonary thromboembolism, and the peak concentrations of plasma cardiac troponin with vWF, GP Ilb/IIla, GMP-140, were significantly positively correlated. The increased VWF indicates that platelet adhesion increased and the pulmonary vascular endothelium was impaired ${ }^{10,11}$, which activated platelets when exposed to blood vessels via vWF ${ }^{12,19}$ and aggravated thrombosis and increased $\mathrm{VWF}^{20,21}$. GP IIb/IIla is the main glycoprotein in the platelet membrane ${ }^{22}$ and mediates platelet and fibrinogen combination, which can be activated by collagen, causing endothelial cell damage by pulmonary thromboembolism, hypoxia, and pulmonary hypertension ${ }^{22}$.

GMP-140 is found in rod cells of the endothelial cells and resting platelets $\alpha$ granule, which is a component of the receptors of VWF, thrombin, collagen, and fibrinogen (Fg), among others, and is important in platelet activation, adhesion, and aggregation ${ }^{23,24}$. In pulmonary thromboembolism, reactive oxygen species and inflammatory factors stimulate endothelial 
cells, inducing GMP-140 expression on the cell surface with a combination of the granular membrane of platelet $\alpha$ granule and serous membrane of endothelial cells, activating platelets to form clots $^{25-27}$. The activated platelets undergo an irreversible activation reaction with the infarction of pulmonary tissue, and more GMP-140 is released to cause further thrombosis ${ }^{12,28}$. Increased levels of vWF, GP IIb/ IIla, and GMP-140 lead to local thrombosisinflammation network formation in the lung and cardiac tissue and clot formation, as well as systemic ischemia and hypoxia, which are related to endothelial cell damage. These events cause myocardial damage, as confirmed in this study.

NO inhalation significantly reduced vWF, GP IIb/IIIa, GMP-140 and cardiac troponin levels. The mechanism may involve inhibition of protein kinase $C$ to downregulate the expression of platelet GMP- $140^{29}$ and vWF. Additionally, the inhibition of fibrinogen binding to the GP Ilb/IIla receptor by NO, which activated soluble guanylate cyclase in the platelets, may also reduce platelet aggregation and GMP-140 expression. Thus, NO inhalation can inhibit platelet aggregation and reduce myocardial damage in pulmonary thromboembolism.

\section{Conclusion}

The increased levels of vWF, GP IIb/IIla and GMP-140 may have played an important role in the myocardial damage, and inhalation of NO would reduce the levels of VWF and GMP-140 and inhibit the expression of GP IIb/ Illa on the platelet membrane, all these change alleviated myocardial damage in massive area pulmonary thromboembolism.

\section{References}

1. Darze ES, Casqueiro JB, Ciuffo LA, Santos JM, Magalhães IR, Latado AL. Pulmonary embolism mortality in Brazil from 1989 to
2010: gender and regional disparities. Arq Bras Cardiol. 2016 Jan;106(1):4-12. doi: 10.5935/abc. 20160001.

2. Yavuz S, Toktas F, Goncu T, Eris C, Gucu A, Ay D, Erdolu B, Tenekecioglu E, Karaagac K, Vural $H$, Ozyazicioglu A. Surgical embolectomy for acute massive pulmonary embolism. Int J Clin Exp Med. 2014 Dec 15;7(12):5362-75. PMID: 25664045.

3. Shonyela FS, Yang S, Liu B, Jiao J. Postoperative acute pulmonary embolism following pulmonary resections. Ann Thorac Cardiovasc Surg. 2015;21(5):409-17. doi: 10.5761/atcs.ra.15-00157.

4. Ergan $B$, Ergün R, Çalışkan T, Aydın K, Tokur ME, Savran Y, Koca U, Cömert B, Gökmen N. Mortality related risk factors in highrisk pulmonary embolism in the ICU. Can Respir J. 2016;2016:2432808. doi: 10.1155/2016/2432808.

5. Konstantinides SV, Torbicki A, Agnelli G, Danchin N, Fitzmaurice D, Galiè N, Gibbs $J S$, Huisman MV, Humbert $M$, Kucher $N$, Lang I, Lankeit M, Lekakis J, Maack C, Mayer E, Meneveau N, Perrier A, Pruszczyk P, Rasmussen LH, Schindler TH, Svitil P, Vonk Noordegraaf A, Zamorano JL, Zompatori $\mathrm{M}$; Task Force for the Diagnosis and Management of Acute Pulmonary Embolism of the European Society of Cardiology (ESC). 2014 ESC guidelines on the diagnosis and management of acute pulmonary embolism. Eur Heart J. 2014 Nov 14;35(43):303369, 3069a-3069k. doi: 10.1093/eurheartj/ ehu283.

6. Jiménez $D$, Lobo JL, Barrios $D$, Prandoni $P$, Yusen RD. Risk stratification of patients with acute symptomatic pulmonary embolism. Intern Emerg Med. 2016 Feb;11(1):11-8. doi: 10.1007/s11739-015-1388-0.

7. Celık T, Balta S, Ozturk C, Yıldırım AO, Iyısoy $A$. The best treatment option in the management of patients with acute massive pulmonary embolism: surgery or thrombolysis? Int J Cardiol. 2016 Jul 1;214:286-7. doi: 10.1016/j. ijcard.2016.03.141.

8. Cho JH, Kutti Sridharan G, Kim SH, Kaw R, Abburi T, Irfan A, Kocheril AG. Right ventricular dysfunction as an echocardiographic prognostic factor in hemodynamically stable patients with acute pulmonary embolism: a meta-analysis. BMC 
Cardiovasc Disord. 2014 May 6;14:64. doi: 10.1186/1471-2261-14-64.

9. Langhorn R, Tarnow I, Willesen JL, KjelgaardHansen M, Skovgaard IM, Koch J. Cardiac troponin I and $\mathrm{T}$ as prognostic markers in cats with hypertrophic cardiomyopathy. J Vet Intern Med. 2014 Sep-Oct;28(5):1485-91. doi: 10.1111/jvim.12407.

10.Lannan KL, Phipps RP, White RJ. Thrombosis, platelets, microparticles and PAH: more than a clot. Drug Discov Today. 2014 Aug;19(8):1230-5. doi: 10.1016/j. drudis.2014.04.001.

11.Lalor PF, Herbert J, Bicknell R, Adams DH. Hepatic sinusoidal endothelium avidly binds platelets in an integrin-dependent manner, leading to platelet and endothelial activation and leukocyte recruitment. Am J Physiol Gastrointest Liver Physiol. 2013 Mar 1;304(5):G469-78. doi: 10.1152/ ajpgi.00407.2012.

12.Proulle V, Furie RA, Merrill-Skoloff G, Furie $B C$, Furie B. Platelets are required for enhanced activation of the endothelium and fibrinogen in a mouse thrombosis model of APS. Blood. 2014 Jul 24;124(4):611-22. doi: 10.1182/blood-2014-02-554980.

13. Kline JA, Hernandez J, Garrett JS, Jones AE. Pilot study of a protocol to administer inhaled nitric oxide to treat severe acute submassive pulmonary embolism. Emerg Med J. 2014 Jun;31(6):459-62. doi: 10.1136/ emermed-2013-202426.

14.Trummer G, Berchtold-Herz $M$, Martin J, Beyersdorf F. Successful treatment of pulmonary hypertension with inhaled nitric oxide after pulmonary embolectomy. Ann Thorac Surg. 2002 Apr;73(4):1299-301. PMID: 11996278.

15.Waldow T, Witt W, Janke A, Ulmer A, Buzin $A$, Matschke K. Cell-cell junctions and vascular endothelial growth factor in rat lung as affected by ischemia/reperfusion and preconditioning with inhaled nitric oxide. J Surg Res. 2009 Nov;157(1):30-42. doi: 10.1016/j.jss.2008.07.042.

16.Qi Y, Qian L, Sun B, Liu L, Wu P, Sun L. Inhaled $\mathrm{NO}$ contributes to lung repair in piglets with acute respiratory distress syndrome via increasing circulating endothelial progenitor cells. PLoS One. 2012;7(3):e33859. doi: 10.1371/journal.pone.0033859.

17.Strijdom H, Chamane N, Lochner A. Nitric oxide in the cardiovascular system: a simple molecule with complex actions. Cardiovasc J Afr. 2009 Sep-Oct;20(5):303-10. PMID: 19907806

18.Turturici M, Roatta S. Effects of gadolinium chloride on basal flow and compressioninduced rapid hyperemia in the rabbit masseter muscle. J Physiol Pharmacol. 2014 Jun;65(3):409-15. PMID: 24930513.

19.Passam FH, Lin L, Gopal S, Stopa JD, BellidoMartin L, Huang M, Furie BC, Furie B. Both platelet- and endothelial cell-derived ERp5 support thrombus formation in a laserinduced mouse model of thrombosis. Blood. 2015 Apr 2;125(14):2276-85. doi: 10.1182/ blood-2013-12-547208.

20.Tabor CM, Shaw CA, Robertson S, Miller MR, Duffin R, Donaldson K, Newby DE, Hadoke PW. Platelet activation independent of pulmonary inflammation contributes to diesel exhaust particulate-induced promotion of arterial thrombosis. Part Fibre Toxicol. 2016 Feb 9;13:6. doi: 10.1186/ s12989-016-0116-x.

21.Vermeersch E, DenormeF, Maes W, De Meyer SF, Vanhoorelbeke K, Edwards J, Shevach EM, Unutmaz D, Fujii H, Deckmyn H, Tersteeg C. The role of platelet and endothelial GARP in thrombosis and hemostasis. PLoS One. 2017 Mar 9;12(3):e0173329. doi: 10.1371/ journal.pone.0173329.

22. Madan M, Berkowitz SD, Tcheng JE. Glycoprotein Ilb/Illa integrin blockade. Circulation. 1998 Dec 8;98(23):2629-35. PMID: 9843473

23.Diaz JA, Wrobleski SK, Alvarado CM, Hawley $\mathrm{AE}$, Doornbos NK, Lester PA, Lowe SE, Gabriel JE, Roelofs KJ, Henke PK, Schaub RG, Wakefield TW, Myers DD Jr. P-selectin inhibition therapeutically promotes thrombus resolution and prevents vein wall fibrosis better than enoxaparin and an inhibitor to von Willebrand factor. Arterioscler Thromb Vasc Biol. 2015 Apr;35(4):829-37. doi: 10.1161/ ATVBAHA.114.304457.

24.Qi CL, Wei B, Ye J, Yang Y, Li B, Zhang QQ, Li JC, He XD, Lan T, Wang LJ. P-selectin-mediated platelet adhesion promotes the metastasis of murine melanoma cells. PLoS One. 2014 Mar 14;9(3):e91320. doi: 10.1371/journal. pone.0091320.

25.Chirinos JA, Heresi GA, Velasquez $H$, Jy W, 
Jimenez JJ, Ahn E, Horstman LL, Soriano AO, Zambrano JP, Ahn YS. Elevation of endothelial microparticles, platelets, and leukocyte activation in patients with venous thromboembolism. J Am Coll Cardiol. 2005 May 3;45(9):1467-71. doi: 10.1016/j. jacc.2004.12.075.

26.Woollard KJ, Lumsden NG, Andrews $K L$, Aprico $A$, Harris $E$, Irvine JC, Jefferis AM, Fang L, Kanellakis P, Bobik A, ChinDusting JP. Raised soluble P-selectin moderately accelerates atherosclerotic plaque progression. PLoS One. 2014 May 20;9(5):e97422. doi: 10.1371/journal. pone.0097422.

27.McEver RP. GMP-140: a receptor for neutrophils and monocytes on activated platelets and endothelium. J Cell Biochem. 1991 Feb;45(2):156-61. doi: 10.1002/ jcb.240450206.

28.Yi W, Li Q, Shen J, Ren L, Liu X, Wang Q, He $\mathrm{S}, \mathrm{Wu} \mathrm{Q}, \mathrm{Hu} \mathrm{H}, \mathrm{Mao} X$, Zhu L. Modulation of platelet activation and thrombus formation using a pan-PI3K inhibitor S14161. PLoS One. 2014 Aug 12;9(8):e102394. doi: 10.1371/ journal.pone.0102394.

29. Moore SF, van den Bosch MT, Hunter RW, Sakamoto K, Poole AW, Hers I. Dual regulation of glycogen synthase kinase 3 (GSK3) $\alpha / \beta$ by protein kinase $C$ (PKC) $\alpha$ and Akt promotes thrombin-mediated integrin $\alpha \mathrm{llb} \beta 3$ activation and granule secretion in platelets. J Biol Chem. 2013 Feb 8;288(6):3918-28. doi: $10.1074 / j b c . M 112.429936$.

\section{Correspondence:}

Zibo Meng

Department of Respiration, Affiliated Hospital

of Hebei University

Baoding 071000 China

Phone: +863125981021

Fax: +863125981688

lizhengdoc@163.com

Received: Apr 10, 2018

Review: June 12, 2018

Accepted: July 10, 2018
Conflict of interest: none

Financial source: none
${ }^{1}$ Research performed at Central Laboratory, Department of Respiration, Affiliated Hospital, Hebei University, Baoding, China. 